\title{
Analysis of MSEs in ICT Domain from Bucharest - Ilfov County by Using Nonaka - Takeuchi Model
}

\author{
Doina I. POPESCU1*, Adriana ALEXANDRU², \\ Sebastian - Ion CEPTUREANU ${ }^{3}$, Eduard - Gabriel CEPTUREANU ${ }^{4}$ \\ ${ }^{1}$ The Bucharest University of Economic Studies, Romana Square, Bucharest, 010374, Romania \\ e-mail: doina.popescu@man.ase.ro (*Corresponding author) \\ ${ }^{2}$ National Institute for Research and Development in Informatics, Averescu Bvd., Bucharest, 011455, Romania \\ e-mail: adriana@ici.ro \\ ${ }^{3}$ The Bucharest University of Economic Studies, Romana Square, Bucharest, 010374, Romania \\ e-mail: sebastian.ceptureanu@man.ase.ro \\ ${ }^{4}$ The Bucharest University of Economic Studies, Romana Square, Bucharest, 010374, Romania \\ e-mail: eduard.ceptureanu@man.ase.ro
}

\begin{abstract}
This paper investigates the extent to which Information and Communication Technology (ICT) adoption and orientations influence the knowledge creation processes encompassed in the Nonaka - Takeuchi model in Romanian mediumsized enterprises (MSEs) from ICT sector. We use econometric analysis in order to confirm hypothesis regarding correlation between Nonaka-Takeuchi model variables and organizational learning. The results, based on a sample of 73 Romanian medium-sized enterprises (MSEs) from Bucharest- Ilfov County, indicate that ICT has a significant positive influence on knowledge creation processes.
\end{abstract}

Keywords: Knowledge creation, Nonaka - Takeuchi model, ICT, Organizational learning.

\section{Introduction}

The nature of firms' competition and the sources of competitive advantage have lately shifted, in many industries, toward knowledge-based resources. This is particularly the case in knowledgeintensive industries, where competitive advantage is highly dependent on the ability of companies to generate and make efficient use of new knowledge-based solutions (Bass et al., 2003; Cho, 2015; Brandi \& Elkjaer, 2011; Chien and Tsai, 2012).

In this context, organizational learning may have a great potential to influence organizational outcomes, such as organizational control and intelligence, competitive advantage, and the exploitation of knowledge and technology (Crossan et al., 1999; Templeton et al., 2002).

Organizations are designing and developing ICT which offer opportunities for enhanced learning (Thomas et al., 2001). As a consequence, some of them overcome the lack of knowledge by employing novel technologies, but the exact measure of how learning is undertaken through these technologies is largely unknown (Small \& Irvine, 2006). In addition, various scholars have expressed concerns about insufficient validation due to lack of empirical research (Dawes et al., 2007; Vince et al., 2002) or the extensive focus on large enterprises, neglecting small and medium ones (Chaston et al., 2001).
Consequently, our paper investigates the extent to which ICT adoption and ICT orientations influence or condition the knowledge creation processes comprised in the Nonaka - Takeuchi model in ICT Romanian MSEs from BucharestIlfov Region.

\section{Literature review}

\subsection{Organizational learning in MSEs}

The term organizational learning was explained by Shrivastava (1983) and states that it is all about the learned behaviors and their interpretation. More recently, with the innovation of social networking and technology, organizational learning evolved in new forms like web 2.0 learning, vicarious learning, social learning and strategic learning (Brandi \& Iannone, 2015; Chi et al., 2008; Ceptureanu et al., 2017a). According to Boja \& Zamfiroiu (2013) the new learning model of the future will be smart, mobile and flexible, which is specific to companies who want to have access to information regardless of time and space constraints.

Many academics consider that organizational learning directly affects different organizational outcomes, i.e. innovative ability, organizational renewal, strategic vision, problem solving, initiating and implementing the change, 
competitive advantage, managerial effectiveness or overall performance (Adams et al., 1998; Attewell, 1992; Bass \& Avolio, 1993; Bierly et al., 2000; Edmondson \& Moingeon, 1998; Goh et al., 2012; Wang and Ahmed, 2003).

It is worth mentioning that the literature does not provide specific insights on organizational learning in MSEs (López et al., 2005; Zagoršek et al., 2009). We can only find single publications which reveal a low formalization of these processes in MSEs in contrast with large sized organizations (Tsang, 1997). Chaston et al. (2001) focused on the analysis of organizational learning styles and their correlation with the entrepreneurial style and job complexity as well as MSEs performance. Other studies focused on Semantic Web technologies, namely the ontologies, in the context of e-learning and e-training systems development (Băjenaru et al., 2016; Galatescu et al., 2011).

Organizational learning represents one of the most important mechanisms to assist MSEs to survive in turbulent environments (Chaston et al., 2001). Due to their specificities (i.e. difficult access to resources, low levels of knowledge, high levels of empowerment etc.), MSEs show a particular behaviour with regard to knowledge processes (Basly, 2007; Yli-renko et al., 2001; Bontis et al., 2002), different than large sized companies.

To explore knowledge generation, our study adopts Nonaka - Takeuchi model (Nonaka \& Takeuchi, 1995; Nonaka et al., 2000), made up of four connected processes for knowledge generation: socialization (S), externalization (E), combination (C), and internalization (I). Organizational learning takes place as employees participate in the processes defined by the model, and, hence, their knowledge is shared, articulated, and made available to others (Huber, 1991; Marwick, 2001; DiBella et al., 1996; Erden et al., 2008; Geisler, 2009).

\subsection{ICT use in MSEs}

Although small and medium-sized enterprises represent a substantial part of the global economy, there is limited knowledge available regarding the adoption of ICT by them, whereby it is only recently that interest in the relationship between MSEs and ICT has begun to be explored in more depth (Iacovou et al., 1995). Nevertheless, the dissemination and assimilation of ICTs in MSEs are ripe for investigation, due to the absence of relevant literature, lack of empirically data and of focused research on this topic (Martin \& Matlay, 2001; Cristescu \& Cristescu, 2009). For instance, in an article of Crawford et al. (2006) is described how in software development industry Taylor based methods heavily and rigorously use documentation for capturing knowledge gained in the activities of a software project life-cycle and that lack on data could strongly affects the results (Crawdord et al., 2006).

Following the main concepts of theory, we use three ICT orientations: informative, communicative and workflow orientations. ICT informative orientation is defined as the use of ICT to provide comprehensive firm electronic information directed to one or more stakeholders (Huzingh, 2000; Bafoutsou \& Mentzas, 2002). The second could be defining as the use of ICT for two-way information exchange (Kalakota \& Robinson, 2000). ICT workflow orientation involves the establishment of predefined electronic processes through firm technologies (Basu \& Kumar, 2002; Fischer, 2004).

Scholars suggest that ICT may improve organizational performance in MSEs if it is used appropriately (i.e. ICT-based processes should be re-designed in ways that outperform traditional work practices). That is why the organizational learning should play an important role for the acquisition of new knowledge that may generate overall efficiency of the business entity.

\section{Model}

Nonaka and Takeuchi suggest four processes of knowledge creation: socialization, externalization, internalization and combination (Chen \& Chen, 2005). Knowledge creation begins with the individual. Making individual knowledge available to others within the organization is the quintessence of the knowledge - based management model. This type of knowledge generation takes place continuously and is present at all levels of the organization, in many cases achieving it is hardly unexpected, without a prior planning (Ceptureanu S.I., 2014).

Development of organizational knowledge represents therefore a process by which the knowledge created by individuals is widely disseminated at the organizational level and shall be incorporated in the network of knowledge of 
the organization (Ceptureanu S.I., 2014). In this regard, Nonaka and Takeuchi identified four ways of conversion of individual knowledge, by which it is articulated and amplified in the framework of the organization, representing the essence of the whole process of generating of organizational knowledge:

- Socialization, the process of sharing tacit knowledge through imitation, observation, participation, and practice in formal and informal communities.

- Externalization, the process of conversion of implicit knowledge into explicit knowledge.

- Combination, the process of conversion of explicit knowledge in other explicit knowledge.

- Internalization, the conversion process of explicit knowledge into implicit knowledge.

Socializing consists in the sharing of knowledge by direct communication between individuals, face-to-face or by typical social interactions, which ensure reaching a mutual understanding by sharing mental models, training between colleagues, mentorship, etc. (Ceptureanu et al., 2017b).

The process of externalization gives a visible form to the implicit knowledge and translates it into explicit. This may be regarded as the quintessence of the process of knowledge generation in which the implicit knowledge becomes explicit, in the form of metaphors and analogies, concepts, hypotheses or models. In this way, the individuals are more easily able to assimilate the knowledge and know-how. The previous implicit knowledge can be written, recorded, outlined or processed into tangible or knowledge in one way or another. At this level it is often needed an intermediary - "journalist" of knowledge - because the transformation of a type of knowledge into another one always presents a high degree of difficulty (Nonaka \& Nishiguchi, 2001).

Once externalized, knowledge become tangible and permanent, ready to be shared to others much easier and used largely in the organization (Ceptureanu S.I., 2014).

The next level of the conversion of knowledge is the combination, which consists in the composition / the integration of the parts of explicit knowledge in a new shape. In this sense, we do not deal with the creation of new knowledge, but with generating a new combination or representation of existing knowledge. In other words, combination refers to the selection and systematization of the concepts in a system of knowledge with another configuration.

The last process is internalization, which consists in the incorporation of recently acquired behaviours or mental models modified by the information and/or learning into the "own knowledge base" by each individual. This process occurs often on the basis of the principle of "learning by doing". Internalization transforms or integrates the shared and/or individual knowledge and experiences into individual mental models. Once interiorized, the new knowledge is then used by employees, which extend and reframe it in accordance with their already available implicit knowledge base. They understand, learn and act in accordance with the new knowledge, and this process is demonstrated by the visible changes in the way of accomplishing the tasks and with regard to the achieved performance (Ceptureanu S.I., 2014).

Tyagi et al. (2001) considers that a major share of new products is built by strategically exploiting the knowledge, technologies, processes and resources of already existing products. In our paper, we develop a theoretical model based in the literature (see Figure 1).

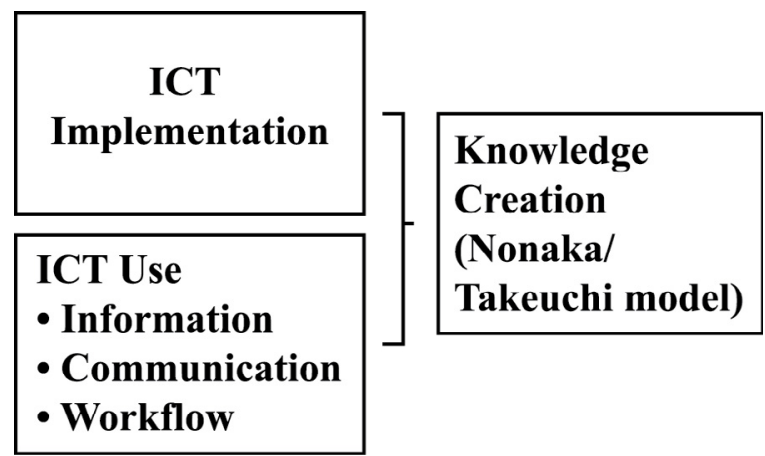

Figure 1. Theoretical model

\section{Hypotheses development}

The literature argues that the amount of knowledge that needs to be captured, stored and shared in a modern organization is not an option, but a necessity. Organizations are "looking to ICT for solutions to their knowledge management" (Ceptureanu et al., 2017b).

Knowledge generation represents the specific activities undertaken by organizations to increase 
their organizational knowledge. Therefore is highly dependent on intensive communication, participative managerial styles, and an "open" organizational culture that accepts new ideas (Ceptureanu S.I., 2014).

According to recent empirical studies on knowledge generation, this process requires a "solid, informal communication network backed by a good information system and an encouraging senior management team that is convinced of its benefits" (Soo et al., 2002).

Nerkar (2003) asserts that "knowledge generation depends on an evolutionary process that involves the recombination of knowledge, or the search, discovery and use of existing, codified, and observable knowledge within the company that builds over time".

Finally we believe that processes developed by Nonaka and Takeuchi model for knowledge generation can be enhanced by ICT use. That is why we propose the following hypotheses:

H1. ICT implementation is directly related to knowledge generation processes.

H1.1. ICT implementation directly influences socialization process.

H1.2. ICT implementation directly influences externalization process.

H1.3. ICT implementation directly influences combination process.

H1.4. ICT implementation directly influences internationalization process.

Even if organizational learning processes can be performed without supporting applications of ICT, technology allows these processes to be performed more effectively (Robey et al., 2002). We consider that the orientation in the implementation of ICT can also have an impact on creating knowledge and, thus, we posit the following:

H2. ICT informative orientation indirectly influences knowledge generation.

H2.1. ICT informative orientation indirectly influences the socialization process.

H2.2. ICT indirectly influences the externalization process.

H2.3. ICT informative orientation indirectly influences the combination process.
H2.4. ICT informative orientation indirectly influences the internationalization process.

ICT communicative and workflow orientations is believed to be directly associated with the processes from Nonaka- Takeuchi model. Communication between employees is essential to organizational learning and can be supported by communicative oriented information that provides communication links between employees and managers (Robey et al. 2002).

H3. ICT communicative orientation directly influence knowledge generation processes.

H3.1. ICT communicative orientation directly influences the socialization process.

H3.2. ICT communicative orientation directly influences the externalization process.

H3.3. ICT communicative orientation directly influences the combination process.

H3.4. ICT communicative orientation directly influences the internationalization process.

Workflow technologies can enhance organizational learning. ICT oriented to communication and workflows are expected to support internalization. Hence, we posit the following:

H4. ICT workflow orientation directly influences knowledge generation.

H4.1. ICT workflow orientation directly influences the socialization process.

H4.2. ICT workflow orientation directly influences the externalization process.

H4.3. ICT workflow orientation directly influences the combination process.

H4.4. ICT workflow orientation directly influences the internationalization process.

\section{Methodology and analysis}

\subsection{Sample and data collection}

Starting from the theoretical arguments presented above, the present study focused on the extent to which ICT adoption and ICT orientations influence or condition the knowledge creation processes encompassed in the Nonaka- Takeuchi model in ICT Romanian MSEs from Bucharest-Ilfov Region. 128 entrepreneurs/CEOs were invited to participate in a questionnaire- based survey by 
Table 1. Variable descriptive

\begin{tabular}{|c|c|c|c|c|c|c|c|c|c|c|}
\hline \multirow[t]{2}{*}{ Variable } & \multirow[t]{2}{*}{ Mean } & \multirow[t]{2}{*}{ S.D. } & \multicolumn{8}{|c|}{ Pearson correlations } \\
\hline & & & SOC & EXT & СОМB & INT & ICT-S & ICT-I & $\begin{array}{l}\text { ICT- } \\
\text { COM }\end{array}$ & $\begin{array}{c}\text { ICT- } \\
\text { TO }\end{array}$ \\
\hline SOC & 3.595 & 0.6909 & 1 & & & & & & & \\
\hline EXT & 3.621 & 0.7741 & $0.571^{\star * *}$ & 1 & & & & & & \\
\hline $\mathrm{COMB}$ & 3.670 & 0.8034 & $0.542^{\star \star \star}$ & $0.518^{\star \star *}$ & 1 & & & & & \\
\hline INT & 3.214 & 0.8115 & $0.573^{* * *}$ & $0.629^{* * *}$ & $0.611^{* * *}$ & 1 & & & & \\
\hline ICT-S & 3.290 & 0.8435 & $0.522^{\star * *}$ & $0.461^{* * *}$ & $0.586^{\star * *}$ & $0.553^{* * *}$ & 1 & & & \\
\hline ICT-I & 3.851 & 0.9724 & $0.213^{\star \star \star}$ & $0.199^{\star \star *}$ & $0.252^{\star * *}$ & $0.165^{\star * *}$ & $0.258^{\star * *}$ & 1 & & \\
\hline $\begin{array}{l}\text { ICT- } \\
\text { COM }\end{array}$ & 2.028 & 1.0829 & $0.131^{\star * *}$ & $0.147^{\star * *}$ & $0.243^{* * *}$ & $0.260^{* * *}$ & $0.212^{* * *}$ & $0.353^{* * *}$ & 1 & \\
\hline ICT-TO & 3.544 & 1.0594 & $0.157^{\star * *}$ & $0.288^{\star * *}$ & $0.239^{\star * *}$ & $0.199^{* * *}$ & $0.162^{\star * *}$ & $0.346^{\star * *}$ & $0.222^{\star * *}$ & 1 \\
\hline
\end{tabular}

evaluation assertions rated on a Likert scale with five options: 1- strongly disagree), 2 - disagree, 3- neutral, 4- agree, and 5- strongly agree from May to August 2017. A structured questionnaire consisting of close-ended questions was developed (see Appendix A). The study assumed an error of $5.5 \%$ for $p=q=50$ and a confidence level of $94.5 \%$ and 73 valid responses were obtained.

The sample was designed to be large enough to analyse the data by means of principal components extraction using SPSS software (version 19) and to provide cogent results. The structure of the statistical population was: the subjects' average age 38 years old $(\mathrm{M}=38.39, \mathrm{SD}=2.34)$, the gender distribution was $92.3 \%$ males and $7.7 \%$ females and the education level 100\% undergraduates.

\subsection{Measures of variables}

A factor analysis was computed aiming at the exploration of the factors deriving from the hypotheses and to establish a pertinent measure of the analysed dimensions. The accuracy of the method was verified by the Bartlett and Kaiser - Olkin test (KMO) as it allows testing the suitability of factor analysis in the context of collected data. The value of the test $(\mathrm{KMO}=$ 0.896 , Sig. $=0.000$ ) indicated the suitability of using the research method. We used the scale of Lee and Choi (2003), which consists of a total of 19 items, to measure the four knowledge creation processes in the Nonaka-Takeuchi model. ICT adoption was measured by 6 items, following the previous literature (Lee \& Choi, 2003).

In order to measure the ICT use orientations, respondents were requested to evaluate ICT informative, communicative and work orientations (see Table 1). We determine the validity of the construct by relating a measuring instrument to previous theoretical framework in order to determine whether the instrument is tied to the concepts and theoretical assumptions employed. Next, in order to obtain evidence of our construct validity, we employed tests for convergent and discriminant validity. Table 2 confirm that each construct is unidimensional and different in terms of factors and that all elements used to operate a particular construct load on a single factor. As shown in Table 2, the reliability and validity tests for scales have shown acceptable values in all cases.

\subsection{Analyses and results}

In order to test the hypotheses, we used hierarchical linear regressions for each knowledge creation process. The dependent variable (each model process) was initially regressed on the ICT implementation variable - Model 1, and then the three ICT use orientations were added - Model 2. We conducted tests to assess the homogeneity of variance of residuals (Hair et al., 1998). Hence, regression results are summarized in Table 3. No significant infringements of these assumptions were observed. Results in Model 1 confirmed support for Hypotheses H1.1, H1.2, H1.3 and H1.4. Model 2 shows that the direct effect of ICT use orientations on externalization, combination and internalization processes was positive since the increment in the squared multiple correlation coefficient $\left(\mathrm{R}^{2}\right)$ was statistically significant. The results support $\mathrm{H} 2.1, \mathrm{H} 2.2, \mathrm{H} 2.3, \mathrm{H} 2.4, \mathrm{H} 3.3$ and $\mathrm{H} 3.4, \mathrm{H} 4.2, \mathrm{H} 4.3$ and $\mathrm{H} 4.4$ while support for H3.1 and H3.2 was not provided. To test the significance of the effects further, we use $\mathrm{R}^{2}$ to compare Model 2 and Model 1. We performed a 
Table 2. Statistics for reliability and validity tests

\begin{tabular}{|l|c|c|c|c|}
\hline Measures & Items & $\begin{array}{c}\text { Reliability } \\
\text { Cronbach } \\
\text { alpha) }\end{array}$ & Convergent validity & Discriminant validity \\
\hline SOC & 5 & 0.708 & $0.451 ; 0.568 ; 0.399 ; 0.498 ; 0.461$ & $0.682 ; 0.755 ; 0.533 ; 0.727 ; 0.687$ \\
\hline EXT & 5 & 0.861 & $0.701 ; 0.673 ; 0.673 ; 0.737 ; 0.635$ & $0.819 ; 0.797 ; 0.795 ; 0.841 ; 0.763$ \\
\hline COM & 5 & 0.792 & $0.572 ; 0.555 ; 0.651 ; 0.603 ; 0.4910 .600 ; 0.522 ;$ & $0.738 ; 0.722 ; 0.801 ; 0.766 ; 0.661$ \\
\hline INT & 4 & 0.788 & $0.712 ; 0.639 ; 0.672 ; 0.681 ; 0.588 ; 0.598$ & $0.772 ; 0.687 ; 0.833 ; 0.779$ \\
\hline ICT SPP. & 6 & 0.855 & $0.398 ; 0.395 ; 0.412$ & $0.811 ; 0.752 ; 0.791 ; 0.795 ; 0.713 ;$ \\
\hline ICT I.O. & 3 & 0.693 & $0.438 ; 0.403 ; 0.539$ & 0.727 \\
\hline ICT C.O. & 3 & 0.702 & $0.427 ; 0.436 ; 0.400$ & $0.529 ; 0.510 ; 0.600$ \\
\hline ICT W.O. & 3 & 0.699 & $0.452 ; 0.571 ; 0.400 ; 0.498 ; 0.462$ & $0.751 ; 0.608 ; 0.851$ \\
\hline
\end{tabular}

Table 3. Regression results

\begin{tabular}{|l|c|c|c|c|c|c|c|c|}
\hline \multirow{2}{*}{ N=73 } & \multicolumn{2}{|c|}{ SOC } & \multicolumn{2}{c|}{ EXT } & \multicolumn{2}{c|}{ COM } & \multicolumn{2}{c|}{ INT } \\
\cline { 2 - 9 } & M1 & M2 & M1 & M2 & M1 & M2 & M1 & M2 \\
\hline Constant & $2.262^{* * *}$ & $2.021^{* * *}$ & $2.217^{* * *}$ & $1.731^{* * *}$ & $1.905^{* * *}$ & $1.484^{* * *}$ & $1.482^{* * *}$ & $1.267^{* * *}$ \\
\hline ICT SPP. & $0.501^{* * *}$ & $0.475^{* * *}$ & $0.457^{* * *}$ & $0.416^{* * *}$ & $0.579^{* * *}$ & $0.527^{* * *}$ & $0.538^{* * *}$ & $0.502^{* * *}$ \\
\hline ICT I.O. & & 0.072 & & 0.018 & & 0.047 & & -0.050 \\
\hline IC\&T C.O. & & -0.007 & & 0.001 & & $0.087^{*}$ & & $0.144^{* * *}$ \\
\hline ICT W.O. & & 0.052 & & $0.215^{* * *}$ & & $0.116^{* *}$ & & $0.101^{* * *}$ \\
\hline F- Value & $100.29^{* * *}$ & $26.14^{* * *}$ & $79.25^{* * *}$ & $25.77^{* * *}$ & $150.01^{* * *}$ & $42.96^{* * *}$ & $121.21^{* * *}$ & $34.78^{* * *}$ \\
\hline Adjusted R & 0.249 & 0.251 & 0.205 & 0.248 & 0.333 & 0.358 & 0.285 & 0.312 \\
\hline Sign. $\Delta$ in $\mathrm{R}^{2}$ & - & 0.251 & - & 0.000 & - & 0.001 & - & 0.003 \\
\hline
\end{tabular}

Wald test to jointly test multiple hypotheses on multiple parameters, using formula:

$$
W_{n}=n g\left(\widehat{\theta}_{n}\right)^{\top}\left[J_{g}\left(\widehat{\theta}_{n}\right) \hat{V}_{n} J_{g}\left(\widehat{\theta}_{n}\right)^{\top}\right]^{-1} g\left(\widehat{\theta}_{n}\right)
$$

and we found out that differences were statistically significant, except for the socialization process (Greene, 2000). The corresponding results are reported in Table 3.

\section{Conclusions}

Our research examines the extent to which ICT adoption and ICT orientations influence the knowledge creation processes encompassed in the Nonaka - Takeuchi model (1995). The empirical analyses demonstrate the importance of adopting a proper ICT orientation if knowledge creation and organizational learning are to be empowered. Results indicate that implementing an ICT informative orientation is not related to the knowledge creation processes.

In our article we did not only highlight the impact of Nonaka - Takeuchi model on organizational learning, we also conceptualized the influence of ICT from a theoretical perspective. Future research may further explore how knowledge generation may influence top executives' decision to pursue initiatives on ICT and how senior managers' attitudes towards building knowledge through learning initiatives influence behaviours of employees.

Also, our paper contributes to the development of empirical research on knowledge generation in an organizational setting as is highlights the boundary conditions of the impact by examining the effect of firms' organizational learning on knowledge management.

This study has some limitations. First, the sample was drawn only from the Bucharest - Ilfov region. For further research, a more comprehensive sample comprising organizations from various parts of Romania may be used in order to ensure a broader perspective. Second, the sample consisted of MSEs, while and according to Caldeira (2002) large sized companies are more prone to implement ICTs. 
Another limitation is its time dimension. The ICT dimensions and variables were studied as well as their impact at the given moment of time, which makes the research a unique picture of the surveyed organizations. In order to analyse the discussed problem thoroughly the research should be replicated on a similar sample in a few years, increasing current knowledge and acknowledgement of what is happening in Romanian MSEs regarding knowledge generation and organizational learning.

\section{Appendix A. Measures}

\section{A. Socialization}

- Gathering of information from sales sites.

- Sharing experience with internal/ external stakeholders.

- Engaging in dialogue with competitors.

- Involving employees in finding new strategies and market opportunities

- Creation of work environment that allows employees to empowerment and use their expertise.

\section{B. Externalization}

- Creative and essential dialogues with stakeholders.

- The use of creative thinking.

- The use of new techniques for concept creation.

- Use of creativity methods to generate ideas and dialogues.

- Subjective opinions.

C. Combination

- Planning strategies.

- Creation of detailed documents on products and services.

- Building of databases on new products/services

- Using the company's managerial and technical data and information to generate new products and services.

- Transmission of newly created concepts.

\section{Internalization}

- Creation of cross-functional development teams.
- Formation of task-force teams for conducting experiments, and sharing results with the entire organization.

- Building and sharing new organizational values.

- Sharing and disseminate management visions through communications with employees.

\section{E. ICT support}

- Delivery of ICT support for internal collaborative works.

- Delivery of ICT support for external collaborative works.

- Delivery of ICT support for communication among employees.

- Delivery of ICT support for searching for and accessing information.

- Delivery of ICT support for simulation and prediction.

- Providing IT support for storing data and information.

\section{F. ICT information orientation}

- Use of ICT network to inform internal stakeholders.

- Use of ICT network to inform external stakeholders.

- Use of ICT network to obtain information about internal and external stakeholders.

G. ICT communication orientation

- Use of ICT network to receive/debate suggestions from employees.

- Use of ICT network to receive customers' suggestions.

- Use of ICT network to participate in discussion forums.

\section{H. ICT workflow orientation}

- Use of ICT network to support processes standardization.

- Use of ICT network to support external processes standardization.

- Use of ICT network to support procedures. 


\section{REFERENCES}

1. Adams, M. E., Day, G. S. \& Dougherty, D. (1998). Enhancing new product development performance: an organizational learning perspective, Journal of Product Innovation Management, 15(5), 403-422.

2. Attewell, P. (1992). Technology diffusion and organizational learning: the case of business computing, Organization Science, 3(1), 1-19.

3. Bafoutsou, G. \& Mentzas, G. (2002). Review and functional classification of collaborative systems. International Journal of Information Management, 22(4), 281-305.

4. Basly, S. (2007). The internationalization of family SME. An organizational learning and knowledge development perspective, Baltic Journal of Management, 2(2), 154- 180.

5. Bass, B. M. \& Avolio, B. J. (1993). Transformational leadership and organizational culture, Public Administration Quarterly, 17(1), 112-121.

6. Bass, B. M., Avolio, B. J., Jung, D. I. \& Berson, Y. (2003). Predicting unit performance by assessing transformational and transactional leadership, Journal of Applied Psychology, 88(2), 207-218.

7. Basu, A. \& Kumar, A. (2002). Research commentary: Workflow management issues in e-business, Information Systems Research, 13(1), $1-14$

8. Băjenaru, L., Smeureanu, I. \& Balog, A. (2016). An Ontology-Based E-Learning Framework for Healthcare Human Resource Management, Studies in Informatics and Control, 25(1), 99-108.

9. Bierly, P. E. III, Kessler, E. H. \& Christensen, E. W. (2000). Organizational learning, knowledge and wisdom, Journal of Organizational Change Management, 13(6), 595-618.

10. Boja, C. \& Zamfiroiu, A. (2013). Input Methods in Mobile Learning Environments, Studies in Informatics and Control, 22(4), 329-338.

11. Bontis, N., Crossan, M. M. \& Hulland, J. (2002). Managing an organizational learning system by aligning stocks and flows. Journal of Management Studies, 39(4), 437-469.
12. Brandi, U. \& Elkjaer, B. (2011). Organizational learning viewed from a social learning perspective, in Easterby-Smith, M. and Lyles, M. A. (eds.), Handbook of Organizational Learning, $2^{\text {nd }}$ ed., 33-42. Wiley, Chichester.

13. Brandi, U. \& Iannone, R. L. (2015). Innovative organizational learning technologies: organizational learning's Rosetta stone, Development and Learning in Organizations, 29(2), 3-5.

14. Caldeira, M. \& Ward, J. (2002). Understanding the successful adoption and use of IS/IT in SMEs: An explanation from Portuguese manufacturing industries, European Journal of Information Systems Journal, 12(2), 121-152.

15. Ceptureanu, E. G., Ceptureanu, S. I., Popescu, D. I. \& Vlad, L. B. (2017a). Two Stage Analysis of Successful Change Implementation of Knowledge Management Strategies in Energy Companies from Romania, Energies, 10(12), 1965.

16. Ceptureanu, E. G., Ceptureanu, S. I. \& Popescu, D. (2017b). Relationship between Entropy, Corporate Entrepreneurship and Organizational Capabilities in Romanian Medium Sized Enterprises, Entropy, 19(8), 412.

17. Ceptureanu, S. I. (2014). Knowledge based economy in Romania: comparative approach, Journal of Applied Quantitative Methods, 9(4), 51-61.

18. Chaston, I., Badger, B., Mangles, T. \& SadlerSmith, E. (2001). Organizational learning style, competencies and learning systems in small UK manufacturing firms, International Journal of Operations \& Production Management, 21(11), 1417-1432.

19. Chen, A. P., \& Chen, M. Y. (2005). A unifying ontology modeling for knowledge management. In Knowledge-Based Intelligent Information and Engineering Systems (pp. 159-159). Springer Berlin/Heidelberg.

20. Chi, M. T., Roy, M. \& Hausmann, R. G. (2008). Observing tutorial dialogues collaboratively: insights about human tutoring effectiveness from vicarious learning, Cognitive Science, 32(2), 301-341. 
21. Chien, S.-Y. \& Tsai, C.-H. (2012). Dynamic capability, knowledge, learning, and firm performance, Journal of Organizational Change Management, 25(3), 434-444.

22. Cho, V. (2015). A study of the impact of organizational learning on information system effectiveness, International Journal of Business and Information, 2(1).

23. Crawford, B., Castro, C. \& Monfroy, E. (January, 2006). Knowledge management in different software development approaches, ADVIS, 304-313.

24. Cristescu, M. P. \& Cristescu, C. I. (2009). The Management of the Informational Enterprises Resources. In $16^{\text {th }}$ International Economic Conference - IECS 2009, published in Industrial Revolutions, From the Globalization and Post-Globalization Perspective, $V$ (pp. 22-27).

25. Crossan, M, Lane, H. \& White, R. (1999). An organizational learning framework: From intuition to institution. Academy of Management Review, 24(3), 522- 537.

26. Dawes, P. L., Lee, D. Y. \& Midgley, D. (2007). Organizational learning in high technology purchase situations: The antecedents and consequences of the participation of external IT consultants, Industrial Marketing Management, 36(3), 285-299.

27. DiBella, A., Nevis, E. \& Gould, J. (1996). Understanding organizational learning capability, Journal of Management Studies, 33(3), 361-379.

28. Edmondson, A. \& Moingeon, B. (1998). From organizational learning to the learning organization, Management Learning, 29(1), 5-20.

29. Erden, Z., Von Krogh, G. \& Nonaka, I. (2008). The quality of group tacit knowledge, Journal of Strategic Information Systems, 17(1), 4-18.

30. Fischer, L. (2004). The Workflow Handbook 2004. Lighthouse Point, FL: Future Strategies Inc.

31. Galatescu, A., Alexandru, A., Zaharia, C. \& Popovici, A. (2011) Semantics and Knowledge-based Systems for Occupational Health Safety, Studies in Informatics and Control, 20(2), 107-120.
32. Geisler, E. (2009). Tacit and explicit knowledge: Empirical investigation in an emergency regime, International Journal of Technology Management, 47(4), 273- 285.

33. Goh, S. C., EllloTt, C. \& Quon, T. K. (2012). The relationship between learning capability and organizational performance: a meta-analytic examination, The Learning Organization, 19(2), 92-108.

34. Greene, W. (2000). Econometric analysis, $4^{\text {th }}$ ed. Upper Saddle River, NJ: Prentice- Hall.

35. Hair, J. F., Anderson, R. E., Tatham, R. L. \& Black, W. C. (1998). Multivariate data analysis with readings. New Jersey: Prentice-Hall.

36. Huber, G. P. (1991). Organizational learning: The contributing processes and the literatures, Organization Science, 2(1), 88-115.

37. Huzingh, E. (2000). The content and design of web sites: An empirical study, Information \& Management, 37(3), 123- 134.

38. Iacovou, C. L., Benbasat, I. \& Dexter, A. S. (1995). Electronic data interchange and small organisations: adoption and impact of technology, MIS Quarterly, 465-485.

39. Kalakota, R. \& Robinson, M. (2000). Roadmap for success. Reading: Addison Wesley Longman.

40. Lee, H. \& Choi, B. (2003). Knowledge management enablers, processes, and organizational performance: An integrative view and empirical examination, Journal of Management Information Systems, 20(1), 179- 228.

41. López, S., Manuel Montes Peón, J. \& José Vazquez Ordás, C. (2005). Organizational learning as a determining factor in business performance, The Learning Organization, 12(3), 227-245.

42. Martin, L. M. \& Matlay, H. (2001). Blanket approaches to promoting ICT in small firms: some lessons from the DTI ladder adoption model in the UK, Internet Research: Electronic Networking Applications and Policy, 11(5), 399- 410.

43. Marwick, A. D. (2001). Knowledge management technology, IBM Systems Journal, 40(4), 814- 830. 
44. Nerkar, A. (2003). Old is gold? The value of temporal exploration in the creation of new knowledge, Management Science, 49(2), 211- 229.

45. Nonaka, I. \& Nishiguchi, T. (2001). Knowledge emergence. New York: Oxford University Press.

46. Nonaka, I. \& Takeuchi, H. (1995). The knowledge-creating company: How Japanese companies create the dynamics of innovation. New York: Oxford University Press.

47. Nonaka, I., Toyama, R. \& Nagata, A. (2000). A firm as a knowledge-creating entity: A new perspective on the theory of the firm, Industrial and Corporate Change, 9(1), 1-20.

48. Robey, D., Ross, J. W. \& Boudreau, M. C. (2002). Learning to implement enterprise systems: An exploratory study of the dialectics of change, Journal of Management Information Systems, 19(1), 17-46.

49. Shrivastava, P. (1983). A typology of organizational learning systems, Journal of Management Studies, 20(1), 7-28.

50. Small, A. \& Irvine, P. (2006). Towards a framework for organizational learning, The Learning Organization, 13(3), 276-299.

51. Soo, C., Devinney, T., Midgley, D. \& Deering, A. (2002). Knowledge management: philosophy, process and pitfalls, California Management Review, 44(4), 129- 150.

52. Templeton, G. F., Lewis, B. R. \& Snyder, C. A. (2002). Development of a measure for the organizational learning construct, Journal of Management Information Systems, 19(2), 175-218.
53. Thomas, J. B., Sussman, S. \& Henderson, J. C. (2001). Understanding "strategic learning": Linking organizational learning, knowledge management, and sense making, Organization Science, 12(3), 331- 345.

54. Tyagi, S. K., Yang, K., Tyagi, A. \& Dwivedi, S. N. (2011). Development of a fuzzy goal programming model for optimization of lead time and cost in an overlapped product development project using a Gaussian Adaptive Particle Swarm Optimizationbased approach, Engineering Applications of Artificial Intelligence, 24(5), 866-879.

55. Tsang, E. W. K. (1997). Organizational learning and the learning organization: a dichotomy between descriptive and prescriptive research, Human Relations, 50(1), 115- 129.

56. Vince, R., Sutcliffe, K. \& Olivera, F. (2002). Organizational learning: New directions, British Journal of Management, 13, S1- S6.

57. Wang, C. L. \& Ahmed, P. K. (2003). Organisational learning: a critical review, The Learning Organization, 10(1), 8-17.

58. Yli-renko, H., Autio, E. \& Sapienza, H. J. (2001). Social capital, knowledge acquisition, and knowledge exploitation in young technology-based firms, Strategic Management Journal, 22(6-7), 587-613.

59. Zagoršek, H., Dimovski, V. \& Škerlavaj, M. (2009). Transactional and transformational leadership impacts on organizational learning, Journal for East European Management Studies, 14(2), 144-165. 